\title{
Simple Method for Aesthetic Symmetrical Post Burn Reconstruction of the Temporal and Sideburn Subunits
}

\author{
MOHAMED A.A. SALEH, M.D., M.R.C.S. (Eng.) \\ The Department of Plastic, Reconstruction, Maxillofacial Surgeries and Burn Management, Faculty of Medicine, \\ Ain Shams University, Cairo, Egypt
}

\begin{abstract}
Post burn scaring and reconstruction of the scalp is common condition, which is challenging to plastic surgeons. Which might lead to social deprivation and severe psychological trauma, and patients always try to hide these areas with scarf, hats, wigs, etc.... Although these attempts are common and useful for the vertex and occipital region, temporo-parietal, temporal, and sideburn are difficult to be camouflaged.
\end{abstract}

Different ways of reconstruction were used including: Serial scar excision, follicular hair transplant, tissue expansion, regional or remote tissue transfer with local or free flaps have been described.

Although tissue expansion is the best and most popular method for scalp reconstruction, the results might be unexpected and displeasing. Searching on English speaking literature, in all previous studies, success was attributed to the expansion process in relation to the size, location of the alopecia and donor area ignoring the importance of achieving the exact or near normal pattern of hair line and symmetry of the temporal, temporo-partial and side burn regions. This is due to the absence of a simple method to guide surgeons while planning and reconstructing this critical zone. In this study, I am presenting a simple method utilizing the tissue expansion for reconstruction of sideburn, temporal, and temporo-partial alopecia to achieve satisfactory, symmetry and near normal reconstruction.

This is a retrospective analysis of prospectively maintained records of 29 patients, was conducted from February 2016 to May 2018 in the Department of Plastic Surgery, Ain Shams University, Cairo, Egypt. Twenty nine patients with scalp burn alopecia of age 6 to 35 years were included in this study. All patients were examined and assessment was done by objective and subjective analysis.

The results shows that by using this simple method to reconstruct temporal and lateral side burn area, it is proven from the objective and subjective evaluation the aesthetic outcome was satisfactory, symmetrical and standardized.

Key Words: Expanded scalp flap - Sideburn reconstruction - Post burn alopecia - Digital sliding caliber.

\section{INTRODUCTION}

Post burn scaring and reconstruction of the scalp is common condition, which is challenging to plastic surgeons, as the scalp is highly specialized area of skin with high density, different patterns and directions of hair covers the skull [1].

Post burn alopecia might lead to social deprivation and severe psychological trauma, and patients always try to hide these areas with scarf, hats, wigs, etc.... Although these attempts are common and useful for the vertex and occipital region, temporo-parietal, temporal, and sideburn are difficult to be camouflaged. Making the reconstruction of the lateral scalp quite important compared to the other parts of the scalp [2].

Different ways of reconstruction were used including: Serial scar excision, follicular hair transplant, tissue expansion, regional or remote tissue transfer with local or free flaps have been described [3-8]. With the exception of tissue expansion, these techniques are partially successful for sideburn and lateral scalp restoration [9-11].

Neumann in 1957 described tissue expansion as a technique for 'growing' extra skin for tissue reconstruction $[\mathbf{1 2 , 1 3}$ ] since no tissue could match the resemblance of the scalp; it has been the mainstay for post burn alopecia [14-16]. Yang et al., 2014 [17]. Described and showed an effective method for the sideburn reconstruction using the expanded reversed temporo-parieto-occipital scalp flap, which provide satisfactory hair density, direction, and hidden scars at both donor and recipient sites. Guzey et al., 2014 [18]. Designed an algorithm to facilitate the reconstruction of the lateral scalp region, guiding surgeons for the appropriate placement of the tissue expanders according to the classification they invented.

Although tissue expansion is the best and most popular method for scalp reconstruction, the results might be unexpected and displeasing, with unnat- 
ural aesthetic outcomes. Searching on English speaking literature, in all previous studies, success was attributed to the expansion process in relation to the size, location of the alopecia and donor area ignoring the importance of achieving the exact or near normal pattern of hair line and symmetry of the temporal, temporo-partial and side burn regions. This is due to the absence of a simple method to guide surgeons while planning and reconstructing this critical zone.

In this study, I am presenting a simple method utilizing the tissue expansion for reconstruction of sideburn, temporal, and temporo-partial alopecia to achieve satisfactory, symmetry and near normal reconstruction.

\section{PATIENTS AND METHODS}

This is a retrospective analysis of prospectively maintained records of 29 patients, was conducted from February 2016 to May 2018 in the Department of Plastic Surgery, Ain Shams University, Cairo,
Egypt. Twenty nine patients with scalp burn alopecia of age 6 to 35 years were included in this study.

\section{Preoperative clinical assessment and planning:}

Patient evaluation included personal and demographic data, type of burn, duration, and any medical or surgical treatment received. The detailed surgical procedure and its stages was explained to the patients or their parents along with the possible outcomes and complications. All tissue expanders used were made of silicone outer shells, with a rectangular shape and a remote internal valve. Preoperative photographs for the affected and healthy side were taken. Examination of donor area of the scalp to exclude presence of previous scars and choose the appropriate tissue expander (dimensions). Detailed measurement of the affected and healthy site and size and a transparent plastic template was made, tracing the healthy side burn and lateral scalp region, which was mirrored over the alopecic area to be reconstructed, Figs. $(1,2)$.
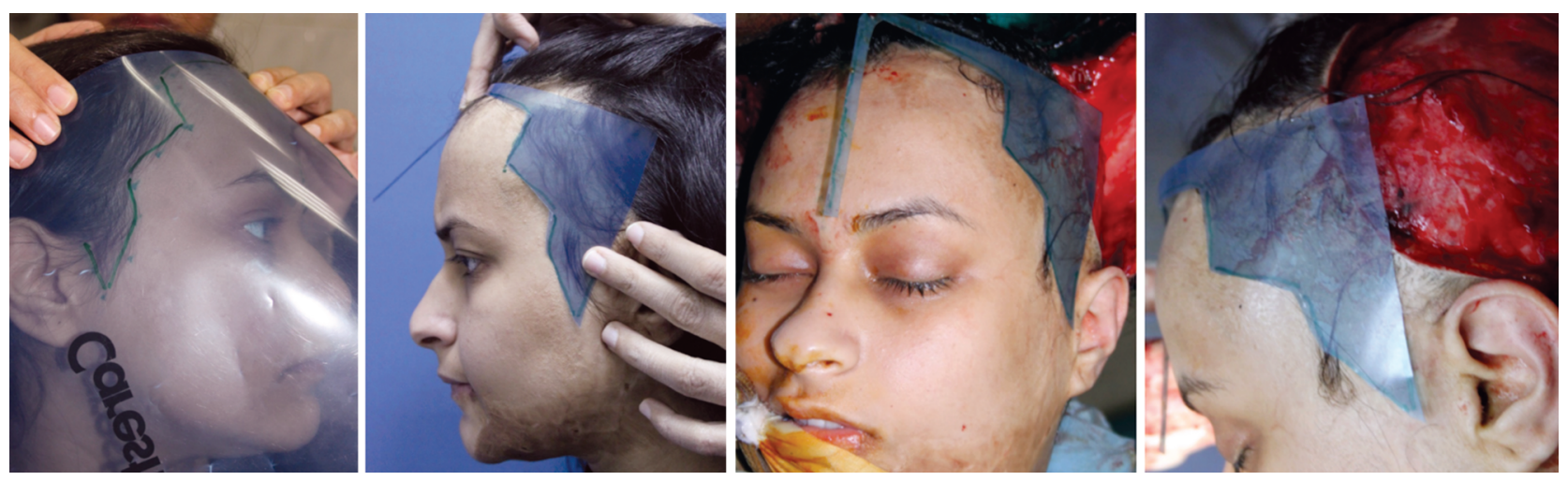

Fig. (1): Transparent template was tailored to match the non-burn side and mirrored to the affected side.

Surgical details: "The surgical technique used were tailored to each patient clinical condition".

\section{First stage: (Application of the tissue expander)}

With the patient under general anesthesia, single dose of broad spectrum antibiotic was administered. Injection of 1:200000 adrenaline: Saline at the site of incision. All incisions were done perpendicular to the direction of expansion at the healthy scalp. A surgical pocket was created between the galea aponeurotica and the pericranium. The surgical pocket was made adequate enough to accommodate the tissue expander by which we could reduce the incidence of expander bends especially at prostheses' corners. After application of the tissue expander within the surgical pocket a close suction drain was used in all patients. Application of the internal valve was carried from the same incision and intraoperative filling the expander with saline (10\% of it volume) was carried to ensure adequate fitting.

The second stage: (Delivery of the tissue expander and reconstruction of the defect). Excision of the scared tissue and flap design were carried considering the size, shape, quality and matching the hair direction with the recipient site. Capsulectomy was done when needed to facilitate mobility of the expanded tissue. A close suction drain was used in all patients and removal of the internal valve was carried from the different incision.

\section{Post-operative care:}

No dressing were applied to the scalp. Broad spectrum antibiotic ointment were applied over the suture line. Patients laid down in semi sitting position. Cold fomentation for the first 48 hours 
followed by hot fomentation up to two weeks over the face. Intravenous antibiotics administered till the drain is removed, shifting to oral route for one week. Drains removed when it's minimal amount (less than 30cc). Patients were instructed to wash their hair and dressing started at the $3^{\text {rd }}$ postoperative day. The skin stitches were removed after two weeks. All patients instructed to follow-up in the outpatient clinic at one, three and six months afterward.

Expansion was started after three weeks with repeated filling using normal saline twice a week. Inflation discontinued when reaching 2-2.5 times the area of alopecia to be reconstructed which is reached at the $10^{\text {th }}$ to $12^{\text {th }}$ post-operative week.

Fig. (2)
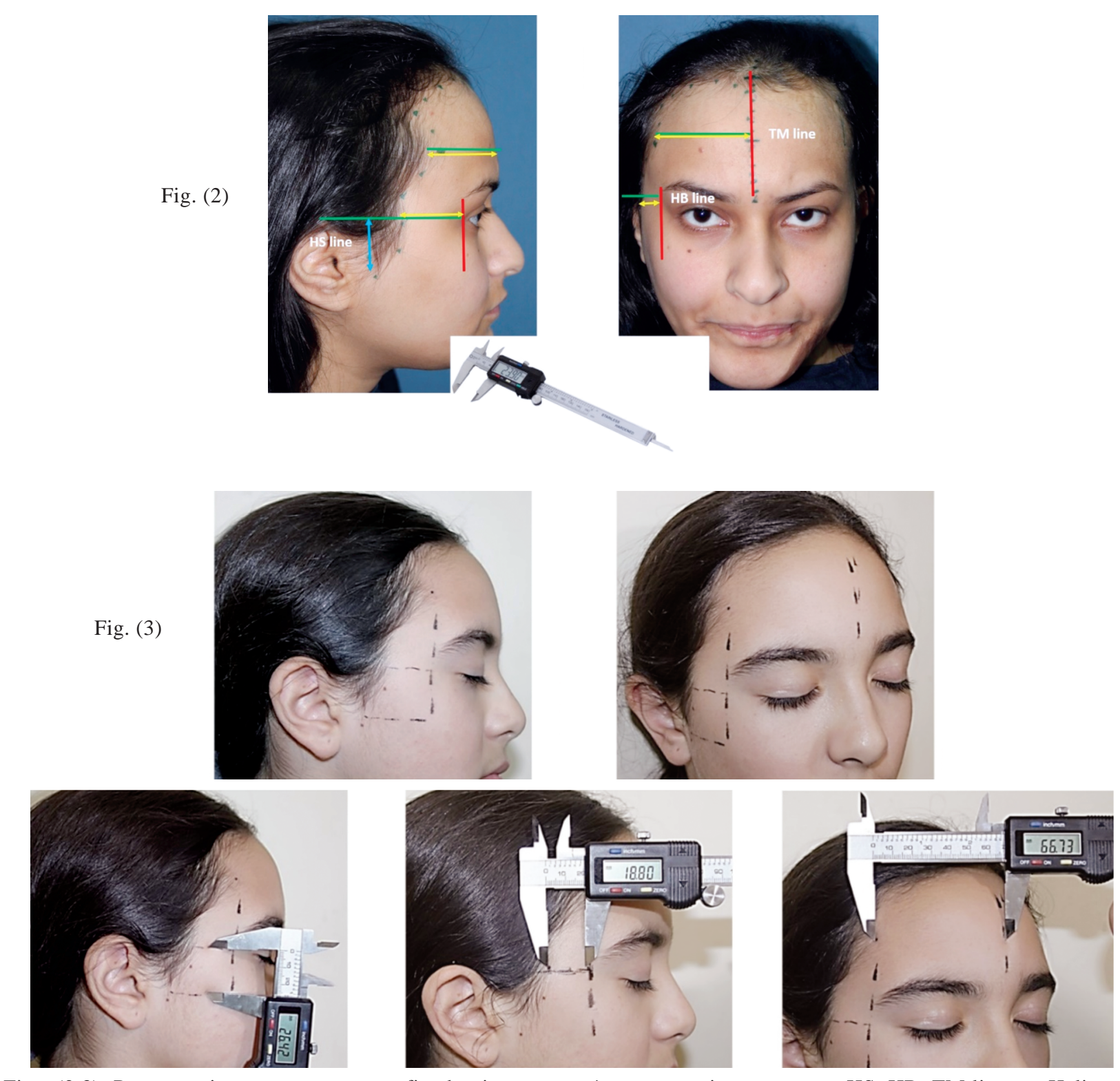

Figs. (2,3): Pre-operative measurements at fixed points to asses' post-operative symmetry. HS, HB, TM line are Helix root

sideburn, Helix brow, and temporal midline lines consecutively.

Post-operative assessment and data collection:

All patients were assessed for the aesthetic outcome and patient satisfaction as regard: Degree of symmetry, hair distribution, density and direction of hair. Patients demographic, history, physical and clinical examination, pre and post-operative photographs and surgical procedures (number and type) and complications were collected. All patients or their parents signed an informed consent to be included in the study.

\section{Symmetry assessment:}

Objective assessment as regard the symmetry of the sideburn and temporal hair line was done by doing pre and post-operative measurements for the health and burn side using the digital sliding caliber at fixed points as shown in Fig. (2). 
The Helix sideburn line: is a measurement taken from the line drawn passing through the root of the helix and the caudal point of the sideburn. The helix brow line: Is a measurement taken from the hairline at the line drawn passing through the root of the helix and the vertical line drawn from the lateral eye brow. Temporal midline line: Is a measurement taken from the most prominent hairline at temporal region to the midline. Subjective assessment was done for patient's satisfaction using the Likert scale, as regard the hair density, direction, scar, and symmetry.

\section{RESULTS}

The study was conducted on 29 patients, 17 males $(56.8 \%)$ and 12 females $(41.4 \%)$ with mean age of 19 years \pm 5 and male to female ratio was
1.42:1, regarding the etiology of burn; 9 patients injured by flame (31\%), 20 patients with scald $(69 \%)$.

Scared region ranged from only sideburn (5 patients; $17.2 \%)$, sideburn and temporal region (15 patients; $51.7 \%$ ) and sideburn, temporal and parietal region (8 patients; $27.6 \%$ ).

Measurements were taken from the normal side and the reconstructed side in specific points forming 3 specific distances, HS distance, HB distance and TM distance all measured with a two fraction of a millimeter.

For each measurement, A line graph was done for all patients showing the similarity between the normal side and the reconstructed side Diagrams (1, 2 and 3$)$.
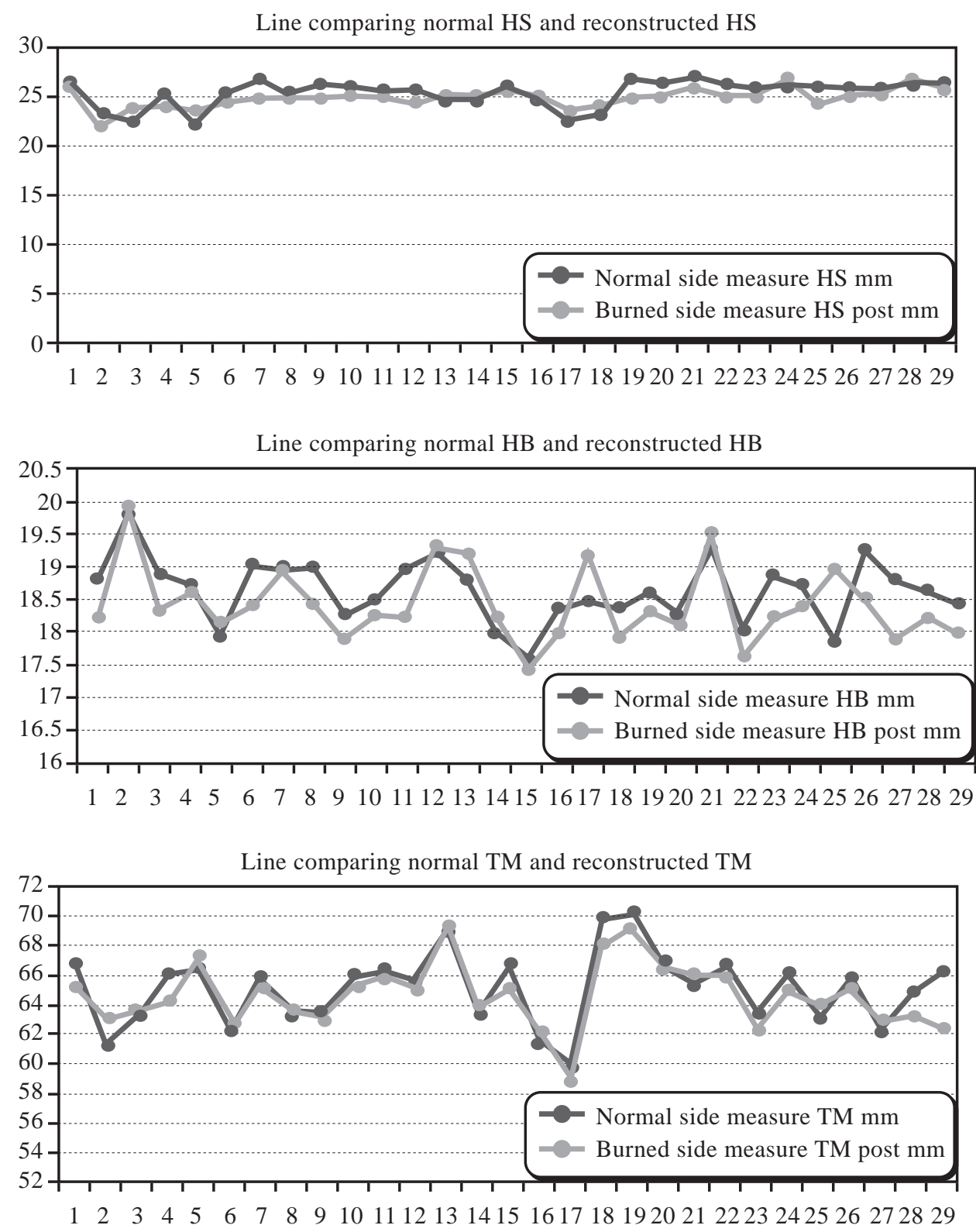

Diagram (1): Showing the normal and burned HS measurement.

Diagram (2): Showing the normal and burned HB measurement.

Diagram (3): Showing the normal and burned HS measurement. 
The mean HS distance of the reconstructed side was $24.96 \mathrm{~mm} \pm 0.96$ compared to the normal side $25.44 \mathrm{~mm} \pm 1.31$ with mean difference $0.88 \mathrm{~mm} \pm 0.46$.

While the mean of the HB distance of the reconstructed side was $18.43 \mathrm{~mm} \pm 0.58$ compared to the normal side $18.63 \mathrm{~mm} \pm 0.48$ with mean difference $0.42 \mathrm{~mm} \pm 0.26$.

In the TM distance the mean of the reconstructed side was $64.58 \mathrm{~mm} \pm 2.12$ compared to the normal side $65.01 \mathrm{~mm} \pm 2.45$ with mean difference $0.91 \mathrm{~mm}$ \pm 0.74 .

A Likert scale questionnaire were conducted to all the 29 patients showing a mean of $8.1 \pm 0.7$ score of answers which is a very good indication that our technique can reach similarity between the normal and reconstructed burned side.

Out of the 29 case only 2 patients had mild infection $(6.9 \%)$ which was treated conservatively and one case with wound dehiscence which needed secondary sutures. No other complications were recorded.
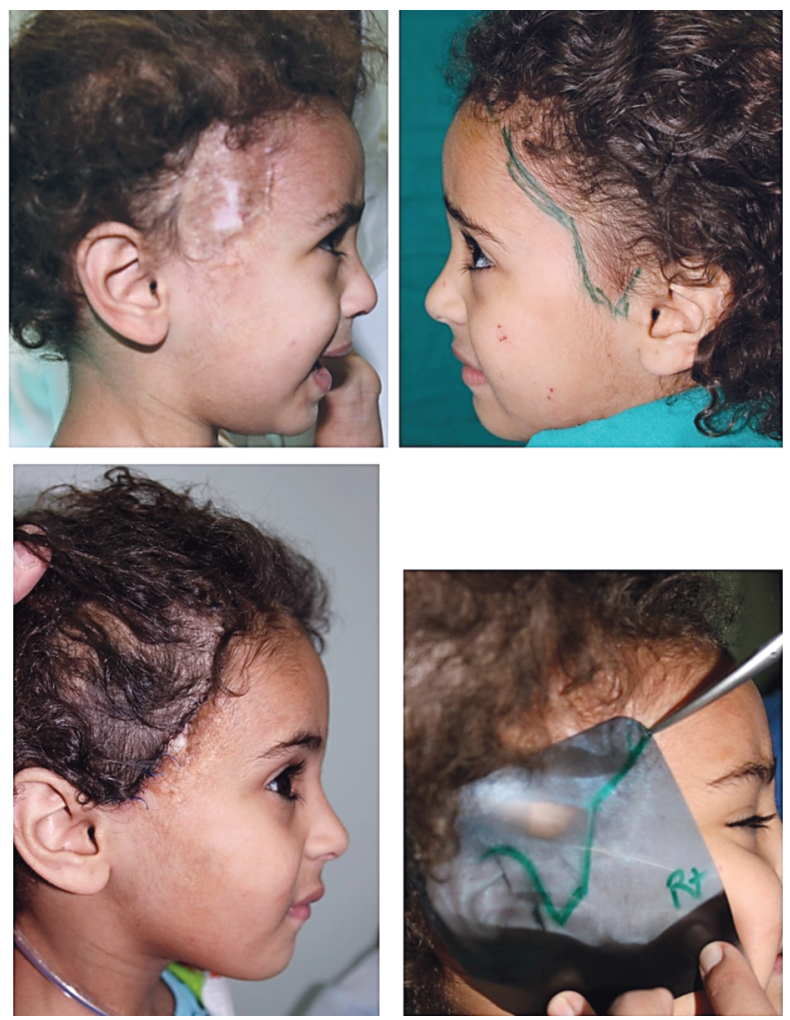

Fig. (5): Upper raw: Pre-operative healthy and burn site, lower raw: Hairline design and postoperative outcome.
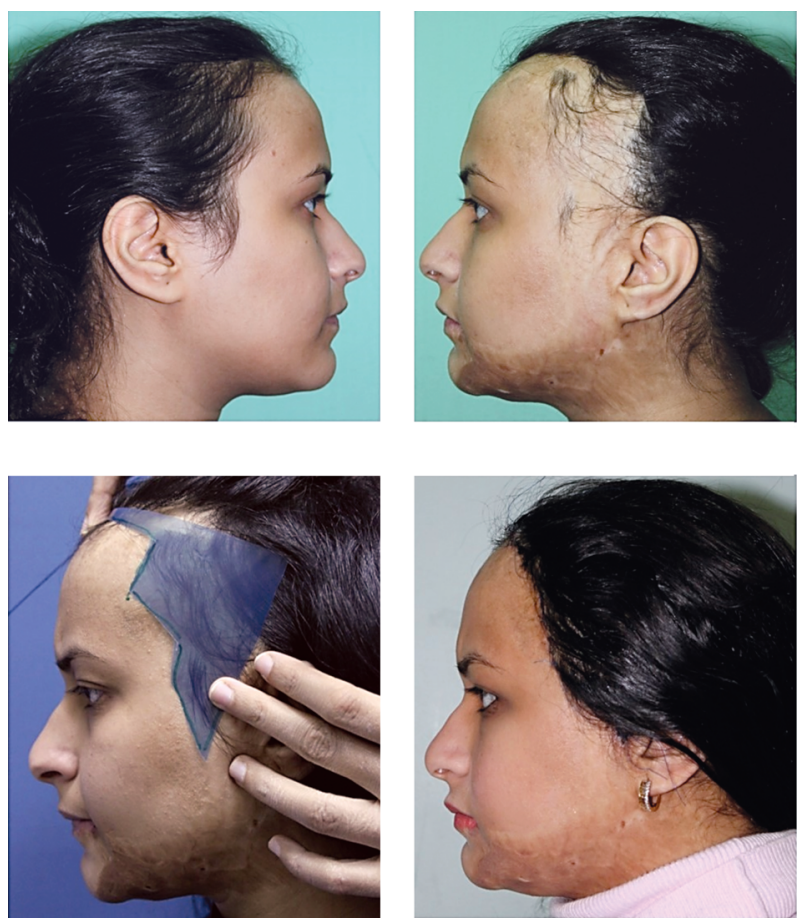

Fig. (4): Upper raw: Pre-operative healthy and burn site, lower raw: Hairline design and postoperative outcome.
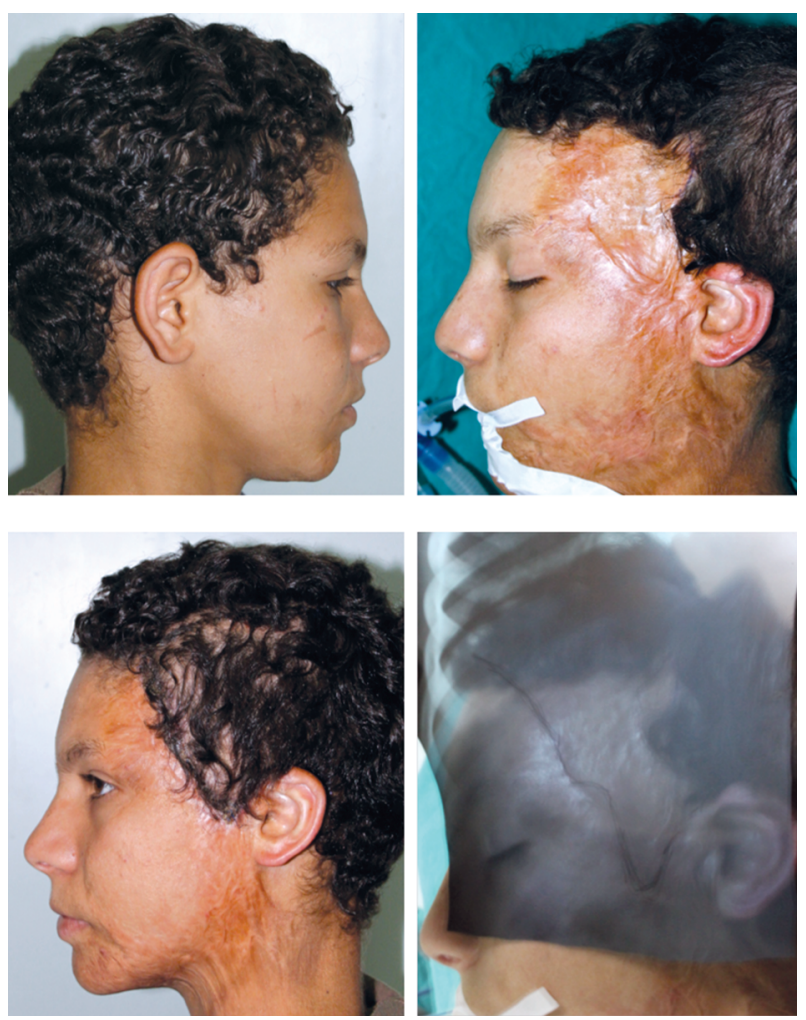

Fig. (6): Upper raw: Pre-operative healthy and burn site, lower raw: Hairline design and postoperative outcome. 

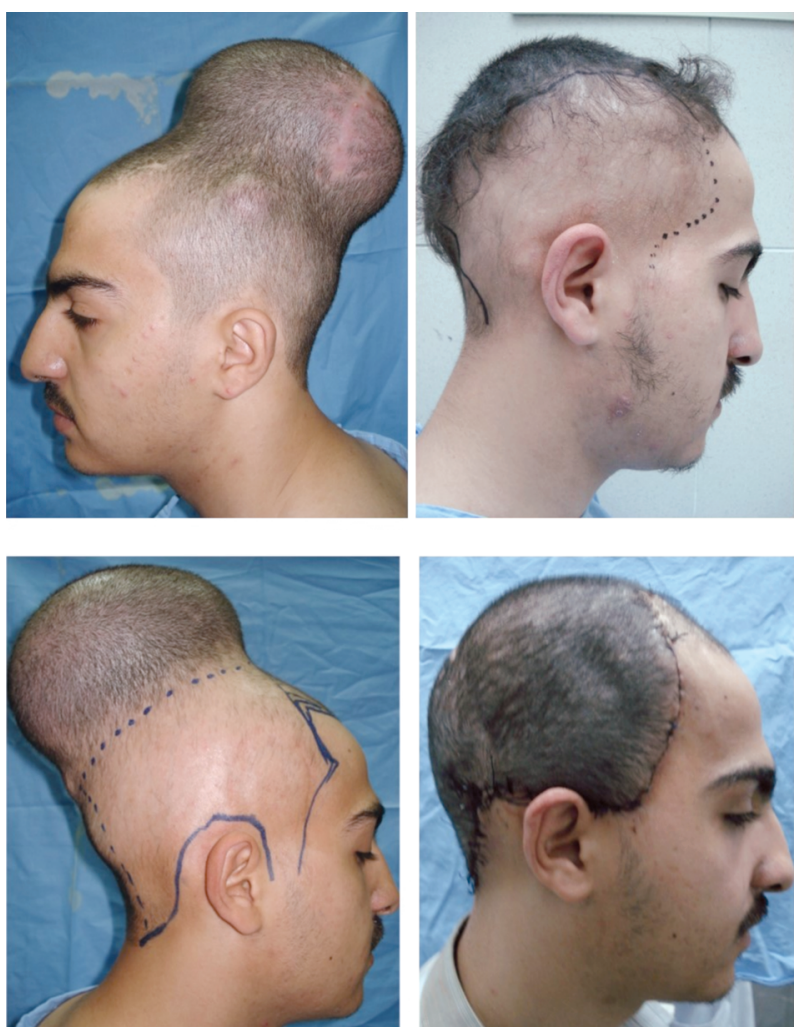

Fig. (7): Upper raw: Pre-operative healthy and burn site, lower raw: Hairline design during expansion and postoperative outcome.
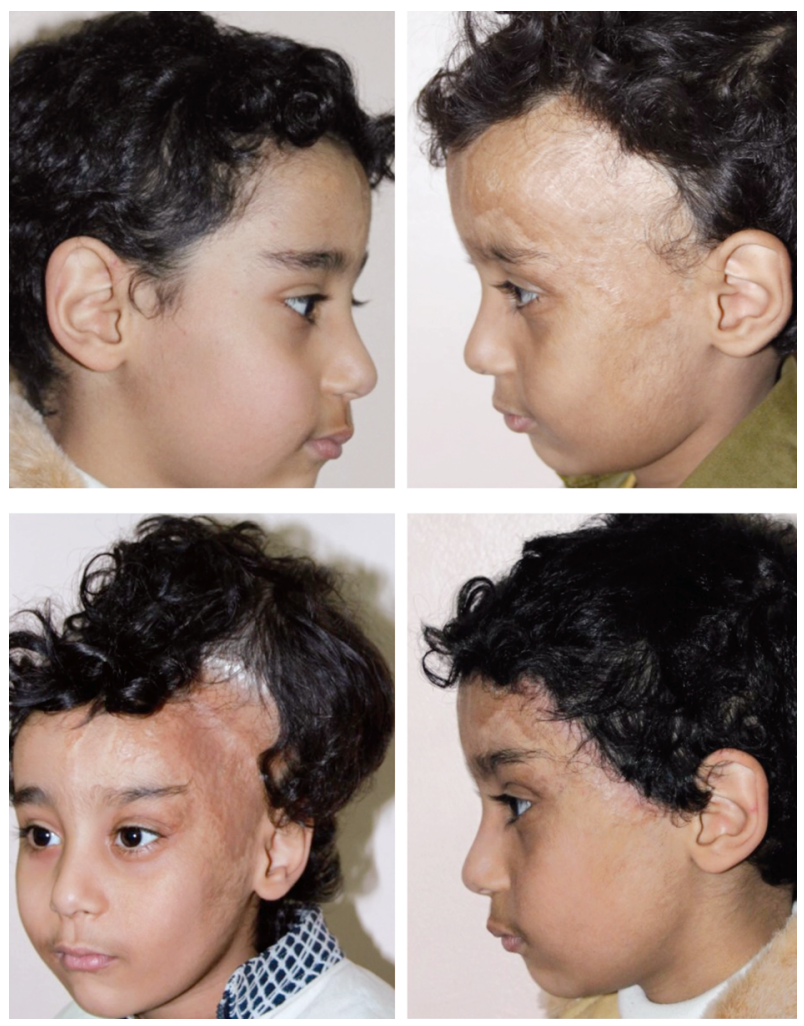

Fig. (9): Upper raw: Pre-operative healthy and burn site, lower raw: During expansion and postoperative outcome.
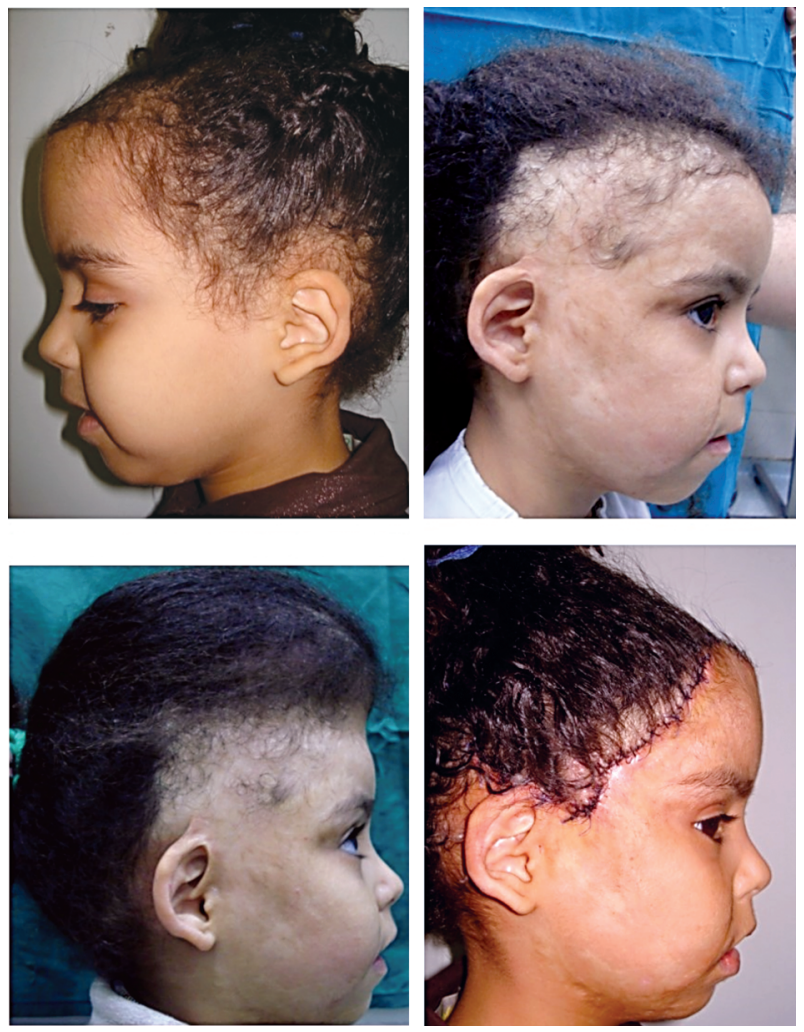

Fig. (8): Upper raw: Pre-operative healthy and burn site, lower raw: During expansion and postoperative outcome.
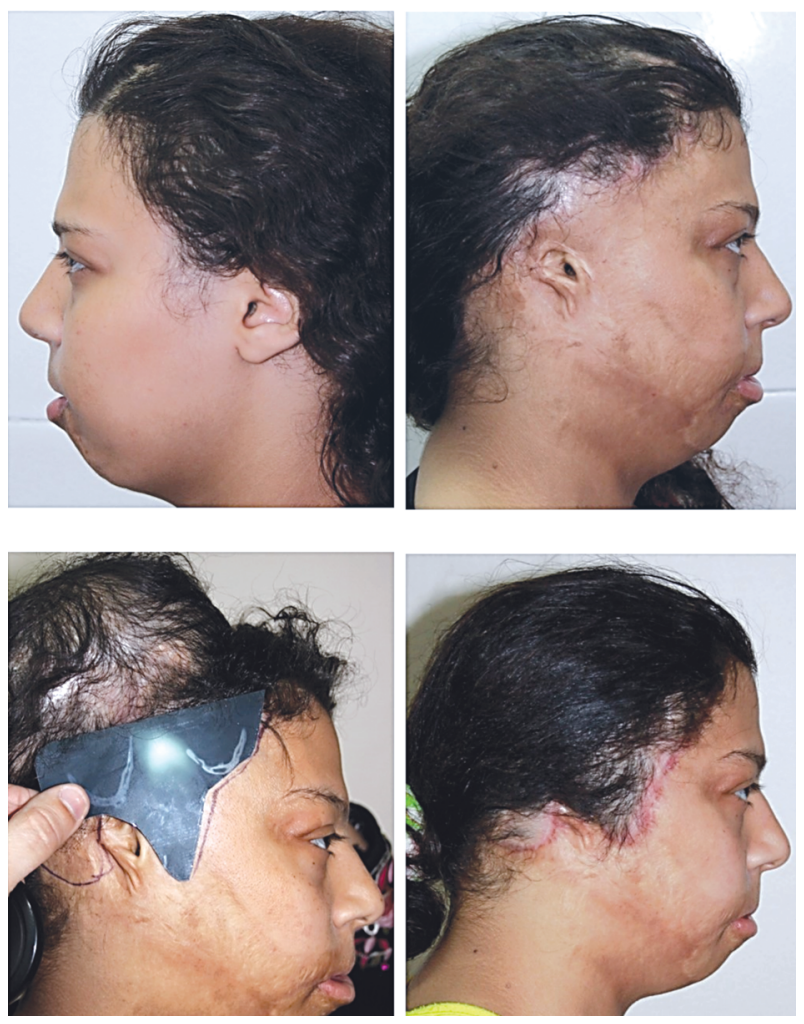

Fig. (10): Upper raw: Pre-operative healthy and burn site, lower raw: Hairline design and postoperative outcome. 

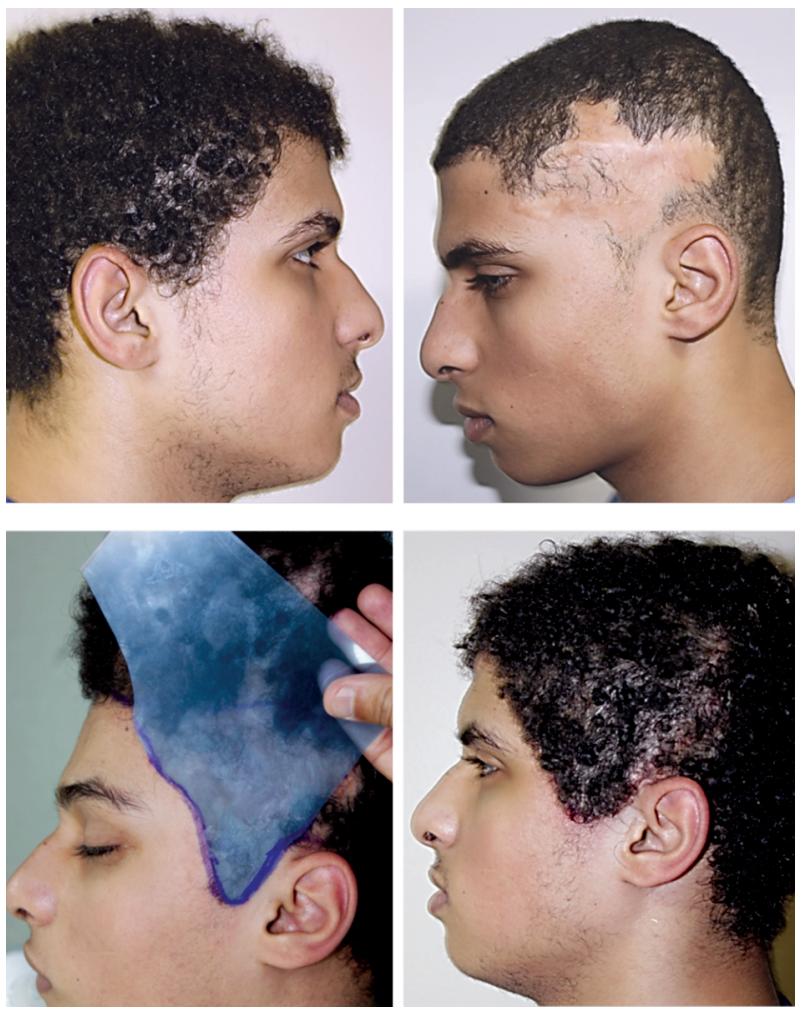

Fig. (11): Upper raw: Pre-operative healthy and burn site, lower raw: Hairline design and postoperative outcome.

\section{DISCUSSION}

Burns cause different degrees of disfigurement, from post burn alopecia limited to the side burn, temporal and tempro-partietal regions. Due to the location of post burn alopecia in this region it is really difficult to hide or camouflage which result in significant psychological trauma.

Lateral scalp and sideburn region reconstruction was not covered in literature as much as total scalp reconstruction. An algorithm for post burn scalp reconstruction was done by Jeong et al. dividing all the scalp into different zones [19]. The study was done according to the site, area involved, quality of the skin and accordingly they proposed different modalities (serial excision, tissue expansion, hair grafting or extension) most appropriate for the affected region. However, there was no recommendation or concern for the temporal, tempro-partietal or sideburn alopecia.

Acquired scalp defects was investigated and algorithm was done by Leedy et al., but it was lacking the lateral scalp reconstruction [20]. Fan and Yang studied 11 patients [21]. Their main concern was the post-operative direction of hair. They recommended for sideburn the following: "An advancement flap to be done if the direction of hair in the expanded area is parallel to the defect. If the hair direction was angled over the expanded area, then a rotation or rotation-advancement flap advised". On the contrary, the postoperative photographs were not similar to their recommendations.

Unger stated that direction of hair is related to its natural fall, and its angle is determined immediately when they exit the scalp [22]. Hair pattern and direction is similar to fingerprints and are unique to each individual. In the lateral scalp region, they demonstrate fanning direction from the vertex [23].

Follicular hair transplantation and serial staged excision could be another modality. However, wide alopecia $(3-5 \mathrm{~cm})$ tend to stretch back after staged excision because of the high incidence of hypertrophic scar and scar widening due to the maximum skin tension exerted $[\mathbf{2 4 , 2 5 , 2 6 ]}$. Also follicle transplantation is technically demanding as regard restoration of natural hair direction which is difficult to achieve in this area [27]. Both modalities are appropriate for scar tissue revision following reconstruction with tissue expanders or in selected patients.

Expanded supraauricular trapezoidal flaps were utilized for partial sideburn reconstruction. However they result in unnatural exaggerated anterior acute angle direction of hair at the sideburn. Splitting the expanded temporal scalp flap splitting at the root of the helix provides more natural hair direction compared to other techniques [28].

As an attempt to get a standardized surgical approach, Guzey et al. [18] designed an algorithm for lateral scalp alopecia reconstruction. They classified the zones of alopecia by their location into three zones, which determines the location of the expander and the flap type. Type I, lateral scalp alopecia; type II, sideburn and temporal region; and type III, isolated sideburn alopecia. Unfortunately the number of cases were limited, comparing the normal to reconstructed side was shown only in one patient, they didn't emphasize on the symmetrical reconstruction and didn't objectively evaluated the esthetic outcome as regard the symmetry and patients satisfaction.

In the present study all patients were examined in the postoperative follow-up. All previous English speaking literature were lacking symmetry assessment and objective analysis for the reconstructed side. We used the digital sliding caliber to measuring three fixed lines to the sideburn and temporal region as shown in Fig. (2). The digital sliding caliber has proven its efficacy and accuracy as 
mentioned in the measurement of the lower lateral cartilage in unilateral cleft lip nasal deformities [29]. The mean HS distance of the reconstructed side was $24.96 \mathrm{~mm} \pm 0.96$ compared to the normal side $25.44 \mathrm{~mm} \pm 1.31$ with mean difference $0.88 \mathrm{~mm}$ \pm 0.46 . While the mean of the HB distance of the reconstructed side was $18.43 \mathrm{~mm} \pm 0.58$ compared to the normal side $18.63 \mathrm{~mm} \pm 0.48$ with mean difference $0.42 \mathrm{~mm} \pm 0.26$. In the TM distance the mean of the reconstructed side was $64.58 \mathrm{~mm} \pm 2.12$ compared to the normal side $65.01 \mathrm{~mm} \pm 2.45$ with mean difference $0.91 \mathrm{~mm} \pm 0.74$.

All patients were photographed in lateral view of the healthy and burn side which is not presented in most of the previous studies, and all patient were subjectively asked about their satisfaction as regard the hair density, direction, scaring and symmetry and a Likert score was done showing a mean of $8.1 \pm 0.7$ score of answers which is a very good indication that our technique can reach similarity between the normal and reconstructed burned side.

Searing on English speaking literature it was recorded that complications ranging from 13 to 30 percent, with complication rates might reach as high as 65 percent [30-37]. Two patients had infection $(6.9 \%)$ in the form of folliculitis treated with local antibiotic ointment and one case with wound dehiscence which entailed partial deflation of the expander and secondary sutures under local anesthesia, and this shows low complication rate if compared to previous studies.

All previous English speaking literature didn't show the detailed operative steps to reach ideal hair line. We are presenting a novel simple technique, using a transparent plastic sheet mirrored from the healthy sideburn and temporal area, which ensure perfect hairline pattern symmetrical to the healthy side, which is proven by our objective and subjective analysis.

\section{Conclusion and recommendation:}

By using this simple method to reconstruct temporal and lateral side burn area, it is proven from the objective and subjective evaluation the aesthetic outcome was satisfactory, symmetrical and standardized. The digital sliding caliber was very accurate and easy to use which could be used as an objective tool in further studies.

\section{REFERENCES}

1- Zuker R.M.: The Use of Tissue Expansion in Pediatric Scalp Burn Reconstruction. 1987. J. Burn Care Rehabilitation. OvidTechnologies (Wolters Kluwer Health), 8 (2): 103-106, 1987.
2- Guzey S., Alhan D., Şahin I., Aykan A., Eski M. and Nişanc1 M.: Our experiences onthe reconstruction of lateral scalp burn alopecia with tissue expanders. Burns. May, 41 (3): 631-7, 2015.

3- Fan J., Wang J. and Nordström R.E.A.: Standardized technique of transplanting micrografts in hair restoration surgery: A practical approach. Dermatol. Surg., 23 (September (9)): 829-33, 1997.

4- Giraldo F., Gonzales C. and Garnica I.: Sideburns reconstruction with an expanded supraauricular trapezoidal flap. Plast. Reconstr. Surg., 100 (July (1)): 257-61, 1997.

5- Oh S.J., Koh S.H., Lee J.W. and Jang Y.C.: Expanded flap and hair follicle transplantation for reconstruction of postburn scalp alopecia. J. Craniofac. Surg., 21 (November (6)): 1737-40, 2010.

6- Felman G.: Post-thermal burn alopecia and its treatment using extensive horizontal scalp reduction in combination with a Juri flap. Plast. Reconstr. Surg., 93 (May (6)): 1268-73, 1994.

7- Barrera A.: The use of micrografts and minigrafts in the aesthetic reconstruction of the face and scalp. Plast. Reconstr. Surg., 112 (September (3)): 883-90, 2003.

8- Rosati P.: Extensive head burns corrected by scalp extension. Dermatol. Surg., 21 (August (8)): 728-30, 1995.

9- Jincai F. and Peiying Y.: Aesthetic reconstruction of burn alopecia by using expanded hair-bearing scalp flaps. Aesth. Plast. Surg., 21 (November-December (6)): 4404, 1997.

10- Eski M. and Şahin I.: The use of tissue expander in the head and neck region. Turk Plast. Surg., 15: 130-5, 2008.

11- Azzolini A., Riberti C. and Cavalca D.: Skin expansion in head and neck reconstructive surgery. Plast. Reconstr. Surg., 90 (November (5)): 799-807, 1992.

12- Biswas B.K., Pal S. and Bag S.: Clinical efficacy of an indigenously developed tissue expander. Available from: http:// www.ijesrt.com/issues\%20pdf\%20file/Archives2014/April-2014/86.pdf. Accessed March 2015, 2014.

13- Ahmad M., Mohmand H. and Surgeon H.R.: Role of tissue expansion in hair restorative surgery. J. Pak. Assoc. Dermatol., 23 (4): 423-427, 2013.

14- Epstein J.S.: Scalp reconstruction: The role of tissue expansion. Hair Transpl Forum Intl., 16: 171-172, 2006.

15- Epstein J.S.: The role of tissue expansion in hair transplant surgery: Presentation of two unique cases. Hair Transpl Forum Intl., 12: 108-109, 2002.

16- McCauley R.L.: Tissue expansion reconstruction of the scalp. Seminars Plast. Surg., 19: 143-152, 2005.

17- Yang Z., Fan J., Tian J., Liu L., Gan C., Chen W. and Yin Z.: Aesthetic sideburn reconstruction with an expanded reversed temporoparieto-occipital scalpflap. J. Craniofac. Surg. Jul., 25 (4): 1168-70, 2014.

18- Guzey S., Alhan D., Şahin I., Aykan A., Eski M. and Nişanc1 M.: Our experiences onthe reconstruction of lateral scalp burn alopecia with tissue expanders. Burns. May, 41 (3): 631-7, 2014.

19- Jeong S.H., Koo S.H., Han S.K. and Kim W.K.: An algorithmic approach for reconstruction of burn alopecia. Ann. Plast. Surg., 65 (September (3)): 330-7, 2010. 
20- Leedy J.E., Janis J.E. and Rohrich R.J.: Reconstruction of acquired scalp defects: An algorithmic approach. Plast. Reconstr. Surg., 116 (September (4)): 54e-72e, 2005.

21- Jincai F. and Peiying Y.: Aesthetic reconstruction of burn alopecia by using expanded hair-bearing scalp flaps. Aesth. Plast. Surg., 21 (November-December (6)): 4404, 1997.

22- Unger W.: Recipient area hair direction and angle in hair transplanting. Dermatol. Surg., 30 (June (6)): 829-36, 2004.

23- Unger W.: The recipient area. In: Unger W.P., editor. Hair transplantation. $3^{\text {rd }}$ ed. New York: Dekker, p. 215-321, 1995.

24- Oh S.J., Koh S.H., Lee J.W. and Jang Y.C.: Expanded flap and hair follicle transplantation for reconstruction of postburn scalp alopecia. J. Craniofac. Surg., 21 (November (6)): 1737-40, 2010.

25- Nordström R.E.: Stretch-back" in scalp reductions for male pattern baldness. Plast. Reconstr. Surg., 73 (March (3)): 422-6, 1984.

26- Nordström R.E. and Devine J.W.: Scalp stretching with a tissue expander for closure of scalp defects. Plast. Reconstr. Surg., 75 (April (4)): 578-81, 1985.

27- Anderson R.D.: The expanded "BAT" flap for treatment of male pattern baldness. Ann. Plast. Surg., 31 (November (5)): 385-91, 1993.

28- Giraldo F., Gonzales C. and Garnica I.: Sideburns reconstruction with an expanded supraauricular trapezoidal flap. Plast. Reconstr. Surg., 100 (July (1)): 257-61, 1997.

29- Saleh M.A.1, Elshahat A., Emara M., Hussein H., Gould
L., Smith D. Jr. and Awad M.A.: Objective tools to analyze the lower lateral cartilage in unilateral cleft lip nasal deformities. J. Craniofac. Surg. Jul., 22 (4): 1435-9, 2011.

30- Elias D.L., Baird W.L. and Zubowicz V.N.: Applications and complications of tissue expansion in pediatric patients. J. Pediatr. Surg., 26: 15-21, 1991.

31- Gibstein L.A., Abramson D.L., Bartlett R.A., Orgill D.P., Upton J. and Mulliken J.B.: Tissue expansion in children: A retrospective study of complications. Ann. Plast. Surg., 38: 358-364, 1997.

32- Iconomou T.G., Michelow B.J. and Zuker R.M.: Tissue expansion in the pediatric patient. Ann. Plast. Surg., 31: 134-140, 1993.

33- Friedman R.M., Ingram A.E. Jr., Rohrich R.J., et al.: Risk factors for complications in pediatric tissue expansion. Plast. Reconstr. Surg., 98: 1242-1246, 1996.

34- Cunha M.S., Nakamoto H.A., Herson M.R., Faes J.C., Gemperli R. and Ferreira M.C.: Tissue expander complications in plastic surgery: A 10-year experience. Rev. Hosp. Clin. Fac. Med. Sao. Paulo., 57: 93-97, 2002.

35- Pisarski G.P., Mertens D., Warden G.D. and Neale H.W.: Tissue expander complications in the pediatric burn patient. Plast. Reconstr. Surg., 102: 1008-1012, 1998.

36- Youm T., Margiotta M., Kasabian A. and Karp N.: Complications of tissue expansion in a public hospital. Ann. Plast. Surg., 42: 396-401; discussion 401-402, 1999.

37- Elshahat A.1: Management of burn deformities using tissue expanders: A retrospective comparative analysis between tissue expansion in limb and non-limb sites. Burns, 37 (3): 490-4, 2011. 